\section{The Evaluation of the Presence of Heavy Metals in Various Lipstick Brands (2015) Avail- able in Delhi-NCR: A Risk Assessment}

\section{SS Agrawal ${ }^{1 *}$ and Namita Kaushik ${ }^{2}$}

1Department of pharmacology, Delhi Institute of Pharmaceutical Sciences \& Research, Delhi, India

${ }^{2}$ Department of pharmacology, Delhi Institute of Pharmaceutical Sciences \& Research, Delhi, India

\begin{abstract}
The aim of this study was to conduct the Pharmacovigilance (PvPi) of cosmeceuticals. On comparing with the previous evaluations, the present studies are indicative of significant decrease of heavy metal levels ( $\mathrm{Pb}, \mathrm{Ar}, \mathrm{Cd}, \mathrm{Ni}, \mathrm{Cr}$, and $\mathrm{Co}$ ) now. Lead is a highly toxic substance that can enter into brain and damage neurons and hence leads to decrease in intellect, particularly in case of children. Also, when lead gets into a person's body, it damages red blood cells in the blood stream and lowers their oxygen-carrying capacity to required tissues, which results in anemia. This study was focused on estimation of heavy metals present in lipsticks and hair colorants, manufactured in the year 2015, and available in Delhi-NCR. The sources of contaminations are more likely to be at the raw-stage levels where unauthenticated ingredients are used. The exposure and use of cosmetics containing heavy metals can be dangerous to health and status of the people, followed by causing huge effect on the economy of any country.

Keywords: Arsenic; Cadmium; Cobalt; Heavy metals; Lead; Lipsticks; Nickel
\end{abstract}

\section{Introduction}

Heavy metals are widely spread in mineral rocks, soil, and water, such as zinc, calcium, and iron. Their absorption causes various metabolic as well as systemic disorders [1]. Drugs are taken to cure an

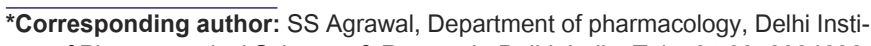
tute of Pharmaceutical Sciences \& Research, Delhi, India, Tel: +91 9810084606 ; E-mail: shyamagrawal2006@gmail.com

Citation: Agrawal SS, Kaushik N (2016) The Evaluation of the Presence of Heavy Metals in Various Lipstick Brands (2015) Available in Delhi-NCR: A Risk Assessment. J Clin Dermatol Ther 4: 023.

Received: November 03, 2015; Accepted: May 12, 2016; Published: June 04, 2016 illness, whereas cosmetics are used, by the person of all age group, to enhance their beauty. Beauty consciousness has led to the development of various new types of cosmetic products, and this development has caught the interest of clinicians and scientists to govern the effects and side effects both. For imparting color shades to the various cosmeceuticals, mineral rocks and pearls are used e.g. Quinazarine Green SS, Tartrazine, Erythrosine etc [2].

Lead affects every other system in a human body including reproductive, neurological, and hematopoieticsystem [3]. Lead affects hematopoietic systems by preventing the synthesis of hemoglobin by the inhibition of various key enzymes involved in the heme synthesis. It is said that the apoptosis may be associated with the oxidative stress induced by lead absorption and DNA damage [4]. The body deposits $90 \%$ of the lead in bones, which increases bone turnover in women. Lead crosses placenta during pregnancy and has been associated with intrauterine fetal death, premature delivery, and low birth weight. Lead is absorbed through skin by absorption directly via inhalation, ingestion, or skin contact occasionally. In adults, about $35-40 \%$ of inhaled lead dust is deposited in lungs and about $60 \%$ of that goes into bloodstream [4].

Arsenic has the properties of metalloid. Exposure is associated with the complications related to peripheral neuropathy and may cause gangrene. After the absorption, arsenic remains stored in liver, kidney, heart, and lungs, whereas the lower amount is found in muscles and neural tissues causing toxicity.

Cobalt, generally found as cobaltous $(+2)$ and cobaltic $(+3)$ states in nature, is a trace element such as iron and nickel in terms of properties. Cobalt is an essential component of vitamin B12 [5]. B12 is a bioavailable form of cobalt since vitamins couldn't be synthesized from dietary cobalt. Excess amount of cobalt leads to carcinogenicity in humans cobalt penetration is shown by an effective barrier in stratum corneum absorption depends on counter ion [6].

Chromium is hazardous in nature even in a very small quantity. It is genotoxic and hepatotoxic in nature [7].

Nickel is another trace element, whose inhalation enhances GI exposure and oral intake increases the sensitization response. Penetration rates of nickel through skin are retarded due to the special ability for keratin. In some people who are sensitive may develop dermatitis too.

Cadmium is a highly toxic element for human body even at low levels. Cadmium and lead can cause significant reduction in gonadotropin binding, which altered the steroidogenic enzyme activity.

\section{Material and Method}

\section{Sample description}

12 samples of 6 different brands of lipstick, manufactured by national as well as international companies, were procured from the local markets and outlets of Delhi-NCR, a metropolitan city in India. The aim behind choosing six brands was to compare the results with the previous findings. All these chosen brands contain lead above the permissible limits. They all are quite famous among females. 
Two samples, each brand bearing same batch number, which were manufactured in 2015, with the same batch number were purchased. One of the samples was kept in safe custody for any legal complications in future, if any.

\section{Methodology}

All the glassware and plastic ware used for the analysis were bought fresh, washed with soap and water, and immersed in $10 \%$ $\mathrm{HNO}_{3}$ for sufficient time. Before using them, all were washed twice with Millipore water to avoid any kind of contamination. Samples and standards were prepared simultaneously-five different quantity concentrations of lead, arsenic, chromium, cobalt, nickel, and cadmium as taken as standard-and standard plot was prepared. For analysis, one gram of sample was taken in an acid-washed container, and $\mathrm{HCl}+\mathrm{H}-$ $\mathrm{NO}_{3}$ (1:1) was added slowly, then it was kept for digestion on sand bath till the sample dried. After cooling, $2.5 \mathrm{ml}$ each of $\mathrm{HCl}$ and $\mathrm{HNO}_{3}$ was added and again kept on sand bath till the fumes disappear. Then, $2 \mathrm{ml}$ of $65 \% \mathrm{HNO}_{3}$ was added, the sample was filtered, and volume was made up to $10 \mathrm{ml}$ with Millipore water.

\section{Variables}

Independent variable-brand of lipstick. Dependent variable-lead, arsenic, chromium, cobalt, nickel, cadmium concentration.

Controlled variables-pressure over the system (1 atm),temperature, volumes of acids added to dissolve solid lipstick $\left(5 \mathrm{~mL} \mathrm{HNO}_{3}\right.$ and 5 $\mathrm{mL} \mathrm{HNO}_{3}$ ), atomic absorption spectrometer, analytical balance scale, amount of lipstick sample added into acid mixture (1g), Millipore water added to lipstick sample time to dissolve solutions $(45 \mathrm{~min})$, temperature of the dissolved solutions $\left(25.0^{\circ} \mathrm{C}\right)$.

\section{Results}

A total result of 12 different samples of lipstick from different brands, which weremanufacturedin2015, were studied for the presence of heavy metals.

The levels found in 8 brands and 4 different shades of Elle-18 were enlisted in the table 1 . The brand selection was based on previous studies.
The levels found in 8 brands and 4 different shades of Elle-18 were enlisted in the table 1 . The brand selection was based on previous studies.

The highlighted cells in the table shows the brands that were with the excess amount of lead beyond permissible limits prescribed for human consumption, as per the International Purity Specifications (IPS), of the FDA and standards for heavy metals (WHO guidelines). The top-shaded parts reflect the lack of proper manufacturing processes by the cosmetic companies and the good enough testing of the products. This could be said that the testing and meeting standards for lead is expensive and raises products costs.

\section{Lead}

Lead was the mostly detected heavy metal in lipstick of many brands. It can be seen clearly in graph 1 that Lakme enrich (13.063ppm), Elle 18 Red (12.382 ppm), Elle 18 brown (10.069 ppm) and Elle 18 light brown $(9.865 \mathrm{ppm})$ exceeds the permissible limits for lead.

\section{Arsenic}

Almost all the brands and shades were found to be having arsenic concentration beyond the permissible limits. Lakme enrich Satin red (3.14 ppm), Elle 18 reddish brown (3.14 ppm), Beauty face (3.01 ppm), Janero Violet (2.635ppm), Elle 18 Brown (2.105 ppm), Elle 18 red (2.105 ppm), L'OréalParis (pure rouge) (2.095 ppm), Maxford lips (red) (2.489 ppm), Janero (dark brown) (3.593 ppm ), Janero (chocolate) (2.259 ppm) (Graph 2).

\section{Cadmium}

Cadmium was present in just trace amount in most of the products, but the shades of Elle 18 were having subsequently higher concentration of cadmium than their peers.

\section{Cobalt}

None of the sample was found to be having Cobalt concentration beyond permissible limits. The permissible limit of Cobalt is $5 \mathrm{ppm}$ under IPS of US FDA.

\begin{tabular}{|c|c|c|c|c|c|c|c|c|}
\hline \multirow{2}{*}{ Product } & \multirow{2}{*}{ Batch No } & MFG & \multirow{2}{*}{$\begin{array}{l}\text { Lead con- } \\
\text { c/1gm }\end{array}$} & \multirow{2}{*}{$\begin{array}{c}\text { Arsenic } \\
\text { (ppm) }\end{array}$} & \multirow{2}{*}{$\begin{array}{c}\text { Cadmium } \\
(\mathrm{ppm})\end{array}$} & \multirow{2}{*}{$\begin{array}{c}\text { Cobalt } \\
(\mathrm{ppm})\end{array}$} & \multirow{2}{*}{$\begin{array}{l}\text { Nickel } \\
\text { (ppm) }\end{array}$} & \multirow{2}{*}{$\begin{array}{c}\text { Chromium } \\
(\mathrm{ppm})\end{array}$} \\
\hline & & BY & & & & & & \\
\hline Jenero (violet) & $425 / \cos$ & Nagar cosmetics & 6.53 & 2.635 & 7.52 & 2.083 & 2.43 & 0.63 \\
\hline Elle 18(red) & B-116 & Hindustan Unilever Limited & 12.382 & 2.105 & 7.14 & 2.104 & 1.62 & 0.861 \\
\hline Elle 18 (light brown) & B-106 & Hindustan Unilever Limited & 9.865 & 2.104 & 7.89 & 2.057 & 1.62 & 0.621 \\
\hline Elle 18 (reddish brown) & B-013 & Hindustan Unilever Limited & 7.62 & 3.14 & 7.965 & 2.184 & 2.4 & 0.15 \\
\hline Elle 18 (orange red) & B-045 & Hindustan Unilever Limited & 5.987 & 0.734 & 3.858 & 2.064 & 1.02 & 0.862 \\
\hline Beauty face (brown) & $495 / \cos$ & - & 8.096 & 3.01 & 6.047 & 2.251 & 1.02 & 1.62 \\
\hline Lakme Enrich (satin red) & B125 & Hindustan Unilever Limited & 13.063 & 3.14 & 7.25 & 2.111 & 1.02 & 0.965 \\
\hline L'OréalParis (pure rouge) & $72 \mathrm{M} 203$ & & 6.055 & 2.095 & 4.466 & 2.09 & 0.67 & 0.265 \\
\hline Maxford lips (red) & $0033 / 12 / \mathrm{cm}$ & & 1.769 & 2.489 & 6.952 & 2.034 & 1.26 & 0.987 \\
\hline Janero (dark brown) & $\mathrm{Na}$ & Nagar cosmetics & 5.68 & 3.593 & 4.456 & 2.259 & 1.35 & 0.569 \\
\hline Janero (chocolate) & $1550 / \cos$ & Nagar cosmetics & 4.59 & 2.259 & 6.072 & 2.157 & 2.123 & 0.253 \\
\hline Permissible limit & & & $20 \mathrm{ppm}$ & $3 \mathrm{ppm}$ & $15 \mathrm{ppm}$ & $5 \mathrm{ppm}$ & $5 \mathrm{ppm}$ & $2 \mathrm{ppm}$ \\
\hline
\end{tabular}

Table 1: Analysis results.

Note: Results shows the analysis of $1 \mathrm{gm}$ of lipstick, whereas one pack of lipstick consists of at least $2 \mathrm{~g}$ of lipstick color. Hence, concentration per pack $=$ Analyzed values x2. 

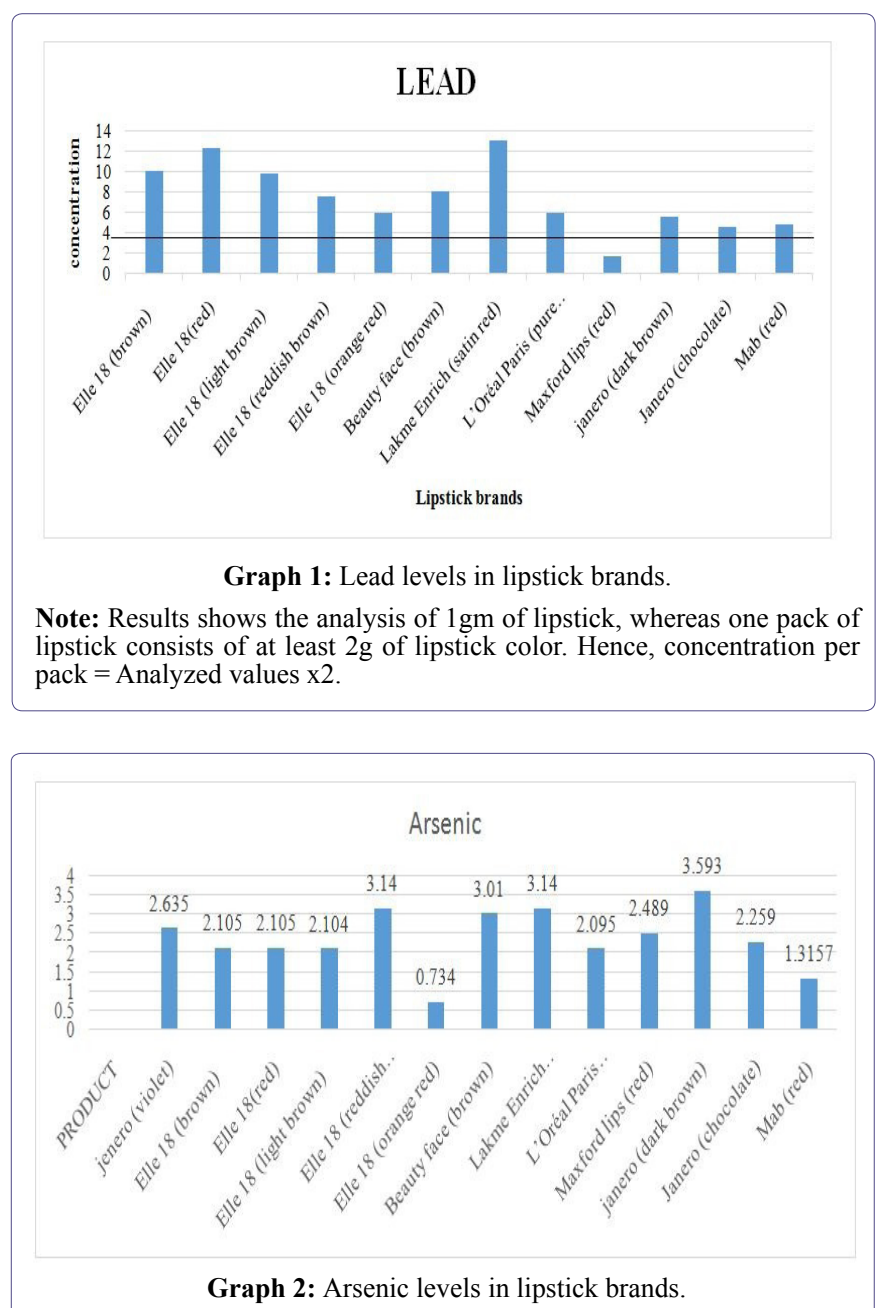

Nickel

Nickel concentration was higher in a local brand naming Mab (red) $(9.6843 \mathrm{ppm})$, whereas a shade of well-known brand Elle 18 (brown) (3.02 ppm) was found to be having higher nickel level than the peers (Graph 3).

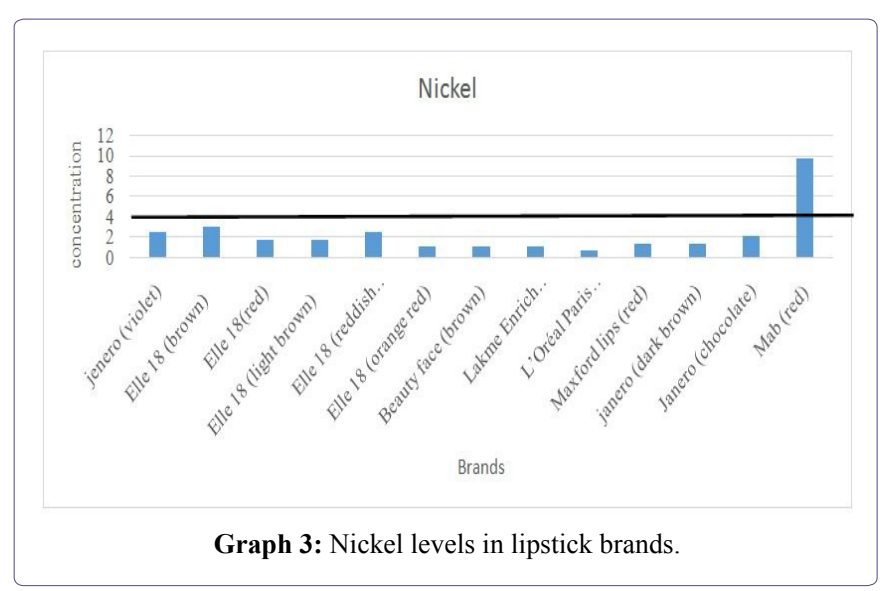

\section{Chromium}

Chromium was found in traces as well and in the permissible limit of $2 \mathrm{ppm}$

\section{Discussion}

In this study, a topical issue of heavy metal concentration in lipstick brands was evaluated and investigated. We can say that the presence of heavy metals (i.e., $\mathrm{Pb}, \mathrm{Co}, \mathrm{Ni}, \mathrm{Cr}, \mathrm{Ar}$, and $\mathrm{Cd}$ ) is due to the ingredients, such as waxes, polishes, emollients, dye pigments, antioxidants, oils, and filling materials, for example, mica, silica, or titanium dioxide.

Limits as per Rule 144 (D \& C 1940) says the permitted synthetic organic colors and natural organic colors used in the cosmetic shall not contain more than 2 parts per million of arsenic calculated as arsenic trioxide. Whereas 20 parts per million of lead is calculated as lead.

However, According to rule 145 of drugs and cosmetic act the use of lead and Arsenic compounds for the purpose of coloring cosmetics is prohibited.

The presence of heavy metal in product like lipstick and other cosmetics may cause harm to females and other population exposed. The long-term effects of heavy metal emit carcinogenicity, and metals like nickel accumulates in our organs, such as kidney and liver, leading to toxicity. Here a need of cosmetovigilance rises to understand the Serious Undesirable Effects (SUE) and various noticed, un-noticed side effects.

On the comparison with the study conducted in 2014, these results are significantly having lower concentration of lead. However, the arsenic levels are increased [8].

Manufacturers should avoid the use of any such ingredient, which is composed of heavy metal adulteration, such as water or waxes.

\section{Conclusion}

The exposure and use of cosmetics with heavy metals can become an economic burden for multi organ dysfunction and danger to health and status of the people globally, followed by causing big effect on the economy of any country. However, it's needed to do quality control and analysis for heavy metals.

The sources of contaminations are more likely to be at the raw stage levels where unauthenticated ingredients are used.

Along with the raw ingredients water is another mode of contamination. Water generally consists of minerals and along with that carries heavy metals. The use of improper and not tested water raises the risk of increased levels.

Compliance and premarketing testing should be mandatory.

\section{Acknowledgment}

Delhi institute of pharmaceutical sciences and research, Delhi is gratefully acknowledged.

\section{References}

1. Tchounwou PB, Yedjou CG, Patlolla AK, Sutton DJ (2012) Heavy metals toxicity and the environment. EXS 101: 133-164.

2. Kumar S, Gupta RN (2012) Regulation for safety and quality of cosmetics vis-a-viscolourants in India compared with other nations. Der Pharmacia Lettre 4: 181-191.

3. World Health Organization (WHO) (2016) Lead poisoning and health, Fact sheet $\mathrm{N}^{\circ} 379$.World Health Organization, Geneva, Switzerland. 
4. Yedjou CG, Milner JN, Howard CB, Tchounwou PB (2010) Basic apoptotic mechanisms of lead toxicity in human leukemia (HL-60) cells.Int $\mathrm{J}$ Environ Res Public Health7: 2008-2017.

5. Das AP, SinghS (2011) Occupational health assessment of chromite toxicity among Indian miners.Indian J Occup Environ Med 15: 6-13.

6. World Health Organization (WHO) (2006) Cobalt and inorganic cobalt compounds. World Health Organization, Geneva, Switzerland.
7. Khalil S, Awad A, Elewa Y (2013) Antidotal impact of extra virgin olive oil against genotoxicity, cytotoxicity and immunotoxicity induced by hexavalent chromium in rat.International Journal of Veterinary Science and Medicine 1: 65-73.

8. Chauhan SB, ChandakA, Agrawal SS (2014) Evaluation of Heavy Metals contamination in Marketed Lipsticks.Int. J of Adv Res2: 257-262. 